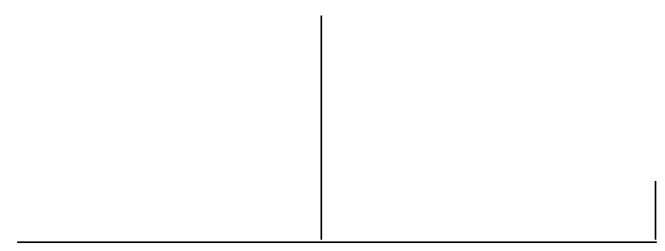

\title{
A construção do caso clínico: uma contribuição da psicanálise à psicopatologia e à saúde mental
}

\author{
Ana Cristina Figueiredo
}

Este texto apresenta uma proposta de construção do caso clínico a partir do desenvolvimento de pesquisa clínica em psicanálise. Destaca três eixos desse procedimento como indicadores metodológicos para o manejo de elementos extraídos dos relatos dos sujeitos, que se apresentam como os seguintes binômios: história/caso; supervisão/construção; conceitos/ distinções. A construção do caso é o ponto central da contribuição da psicanálise tanto para a psicopatologia, por meio da construção diagnóstica e dos indicadores para o tratamento, quanto para a saúde mental, por meio de sua aplicação nos diferentes dispositivos de atenção psicossocial e no trabalho em equipe interdisciplinar.

Palavras-chave: Caso clínico, psicanálise, psicopatologia, saúde mental 
Saúde mental, psiquiatria e psicanálise

O campo da saúde mental é amplo e bastante heterogêneo, tanto no que diz respeito às referências teórico-práticas, quanto ao conjunto de instituições envolvidas na atenção e cuidados da rede pública. Não podemos aspirar a uma homogeneização do campo sob pena de reduzir a sua complexidade a uma visão simplista de saúde pública (Garcia, 2002a, 2002b). Essa variedade abrange desde os programas comunitários, com uma atuação ainda muito restrita nos PSF (Programa de Saúde da Família), passando pelos ambulatórios e pelos CAPS (Centro de Atenção Psicossocial), onde se define uma proposta de reabilitação e ressocialização, culminando nos hospitais psiquiátricos, onde se encontra a psiquiatria em seu território por excelência.

Ao incluirmos a psiquiatria no conjunto dos dispositivos da saúde mental, estamos indicando a qualidade multiprofissional e interdisciplinar desse campo, e recusando uma certa oposição entre psiquiatria e saúde mental que em nada seria benéfica para nosso trabalho, seja na clínica ou na política institucional. Além disso, a psiquiatria é o campo no qual historicamente se desenvolveram os conceitos psicopatológicos, e hoje temos aí diferentes disciplinas convergindo na direção do diagnóstico, da localização do pathos do sujeito, como balizador do tratamento, formando um novo campo para a psicopatologia.

A psicanálise, herdeira da psiquiatria, tem como sua herança a própria psicopatologia. Basta ver os grandes nomes alemães - principalmente Kraepelin e Bleuler - até os franceses como Charcot, seu mestre, Liébault, Bernheim, e mesmo Janet, cuja concepção de inconsciente Freud refuta claramente, propondo o contrário: em vez de astenia psíquica, excitação de traços de memória. Freud, ao tomar seu rumo na direção do inconsciente, lança a psicanálise numa nova referência que redimensiona o alcance do diagnóstico, indo da descrição à dinâmica; do fenômeno à estrutura (Figueiredo \& Machado 2000). Um novo campo aí se delineia por oposição ao campo fenomênico-descritivo da psiquiatria e da psicopatologia geral, a saber: o campo do inconsciente e suas formações (Freud) ou o campo do Outro (Lacan). Essa concepção rompe com as concepções anteriores de diagnóstico e tratamento da psiquiatria criando novas exigências para ambos e abrindo uma nova porta para a psicopatologia. 
Nosso trabalho se desenvolve no campo da saúde mental e da psiquiatria, trazendo essa dimensão que chamamos de campo do inconsciente ou campo do Outro para retomar a psicopatologia em outros termos.

Torna-se necessária uma proposta que contemple diferentes formações profissionais e, conseqüentemente, diferentes referências teóricas, de modo a não reduzir os instrumentos clínicos da psicanálise a uma banalização de seu uso ou a uma supervalorização de seus conceitos. Formulando de outro modo: é preciso localizar qual seria a contribuição específica da psicanálise hoje para a psicopatologia e para a saúde mental. E acrescentaríamos: é preciso apontar o sentido do diagnóstico, ao se incluir aí o sujeito do inconsciente.

No campo da saúde mental teríamos ainda uma questão de fundo, a saber: como constituir um solo comum de trabalho para diferentes profissionais que não teriam qualquer compromisso com uma formação em psicanálise, mas poderiam se valer de sua contribuição?

Essas questões se imbricam partindo do geral - o campo da saúde mental - para o particular - o diagnóstico. A psicanálise introduz aí uma concepção que avança do particular para o singular, retomando o geral a partir dos efeitos colhidos. A ação clínica atua sobre o geral, dado por determinadas diretrizes do campo da saúde mental, como: a reabilitação, a cidadania, a autonomia e a contratualidade, que visam ampliar as relações sociais dos usuários e fazer proliferar suas possibilidades. O singular, nesse caso, seria a articulação do particular de uma referência diagnóstica (histeria, esquizofrenia paranóide, etc.) com o movimento do sujeito do inconsciente. Aqui, se dá uma primeira diferença: o sintoma não vai sem o sujeito, nem o sujeito pode ser pensado sem o seu sintoma. Um constitui o outro, melhor dizendo, um se constitui no outro, o sujeito através do sintoma e vice-versa. Nesse sentido, diagnóstico e tratamento seriam indissociáveis e intercambiáveis: o tratamento também definiria o diagnóstico e não apenas o contrário.

Na psiquiatria atual, não há um diagnóstico do sujeito e sim de uma coleção de fenômenos que nada dizem a respeito dele. Um exemplo gritante disso ocorre com a categoria diagnóstica de histeria. De acordo com os manuais diagnósticos em psiquiatria (CID 9 e 10, DSM III e IV), a histeria "sumiu do mapa", não existe mais, acabou. Existem descrições de todo tipo que fragmentam essa categoria em síndromes e transtornos: dissociativo, conversivo ou somatoforme, histriônico, para citar os principais. Assim, a histeria só existe se atrelada à concepção de inconsciente e, portanto, à própria psicanálise. A psicanálise faz a histeria existir.

Entretanto, o que interessa marcar não é o fato de ressuscitar uma determinada categoria psicopatológica entre outras com o mesmo caráter descritivo da psicopatologia geral. Isso seria cair num relativismo classificatório, fazendo variações sobre um mesmo tema. O que interessa é que a psicanálise, ao 


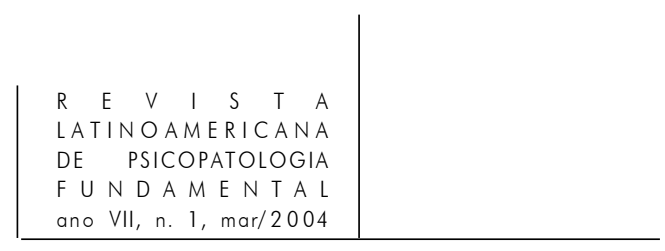

fazer a histeria existir, primeiramente, reconhece uma dívida, já que foi a histeria, melhor dizendo, as histéricas que fizeram a psicanálise existir. E, o que é mais importante, porque a maneira de fazer o sujeito existir é trazer à cena do tratamento o sujeito do inconsciente que se apresenta por meio de seu sintoma. É essa articulação que muda o eixo da discussão diagnóstica e de tratamento (Figueiredo \& Tenório, 2001).

Nas psicoses acontece algo semelhante, se não evocarmos o sujeito com sua palavra e sua responsabilidade desde o primeiro momento, se só o tutelarmos, estaremos decretando o fracasso da clínica e de qualquer transformação na psiquiatria (Tenório, 2001).

Essa relação estreita do sujeito ao sintoma - seja o sintoma neurótico ou as produções psicóticas -, por si já marca uma diferença radical com a concepção funcionalista-organicista de uma certa psiquiatria e sua psicopatologia, que se propõe justamente a separar os dois termos, a não estabelecer qualquer ligação entre eles e, portanto, a distinguir ao máximo o diagnóstico do tratamento, tanto no método quanto na dinâmica.

Se o sintoma não vai sem o sujeito, e esse sujeito é o do inconsciente, o sintoma, como já sabemos, é uma formação (neurose) ou uma exposição do inconsciente (psicose). Lacan refere-se ao inconsciente na psicose como estando "a céu aberto". Um estudo de caso, então, não pode mais ser um relato compilado de acontecimentos e procedimentos dispostos em uma seqüência com critérios pré-estabelecidos a serem preenchidos. Este é o caso da anamnese, que resulta na súmula psicopatológica padronizada que viceja nas sessões clínicas da psiquiatria. Aqui está a diferença, todo o esforço diagnóstico deve se deslocar dessa assepsia para trazer à cena o sujeito e suas produções. E este só aparece pela via do discurso, no qual podemos localizar seu sintoma ou seu delírio.

\section{A construção do caso}

Podemos sintetizar a contribuição da psicanálise para a psicopatologia e para a saúde mental no que denominamos a "construção do caso". Tomemos cada termo.

Construção é diferente de interpretação, por exemplo. A construção é um arranjo dos elementos do discurso visando a uma conduta; a interpretação é pontual visando a um sentido. Eis uma primeira diferença. A finalidade da construção deve ser justamente a de partilhar determinados elementos de cada caso em um trabalho conjunto, o que seria impossível na via da interpretação. Assim, a construção pode ser um método clínico de maior alcance. 
O outro termo, caso, se refere ao latim cadere, que quer dizer "cair". Segundo Viganò $(1999$, p. 51): “... ir para fora de uma regulação simbólica; encontro direto com o real, com aquilo que não é dizível, portanto impossível de ser suportado".

Quanto à clínica, sabemos que vem do grego kline, leito; o sentido da clínica é o debruçar-se sobre o leito do doente e produzir um saber a partir daí. Em suma, a "construção do caso clínico" em psicanálise é o (re)arranjo dos elementos do discurso do sujeito que "caem", se depositam com base em nossa inclinação para colhê-los, não ao pé do leito, mas ao pé da letra. Incluímos aí também as ações do sujeito, entendendo que são norteadas por uma determinada posição no discurso. Convém um aparte para esclarecermos que a fala (parole) tem a dimensão do enunciado (os ditos) e da enunciação (o dizer), que seria a "posição no discurso". Nunca é demasiado lembrar que o caso não é o sujeito, é uma construção com base nos elementos que recolhemos de seu discurso, que também nos permitem inferir sua posição subjetiva, isto é, se fazemos uma torção do sujeito ao discurso, podemos retomar sua localização baseando-nos nesses indicadores colhidos, do dito ao dizer. Aqui temos um método aplicável a diferentes contextos clínicos.

Como se daria então a construção de um caso, tomando as premissas necessárias mencionadas acima?

Tomando-se por base o trabalho da equipe de pesquisa clínica em psicanálise, que conta com participantes que são psicanalistas, pesquisadores e alunos ligados ao Instituto de Psiquiatria IPUB/UFRJ e, mais recentemente, ao Programa de Pós-graduação em Teoria Psicanalítica da UFRJ, desenvolvemos um método que permite recolher da experiência clínica seus elementos de base para podermos reter dessa experiência algo transmissível e avaliável de cada caso (Figueiredo et al., 2001). Recortamos o que chamamos de binômios da construção do caso, isto é, balizadores para nos indicar o caminho. São eles:

História $\leftrightarrow$ Caso:

Vem se produzindo em nossas discussões uma interessante distinção entre esses dois termos. O relato clínico que se apresenta rico em detalhes, cenas e conteúdos é a história. O caso é produto do que se extrai das intervenções do analista na condução do tratamento e do que é decantado de seu relato. Portanto, a história pode ser fatigante, se muito detalhada, e o caso será morto se for reduzido apenas a uma fórmula. Estabelece-se aí um binômio que retoma, então, a idéia de uma formalização necessária do relato que não se reduz a uma teorização formal nem a uma elaboração de saber sobre os problemas do paciente. Pelo contrário, trata-se sim de colocar em jogo os significantes do sujeito, suas 


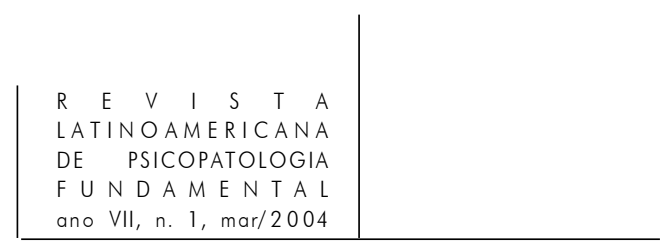

produções com base na elaboração em análise, e a resposta do analista em seu ato com os efeitos que daí advenham para cernir certos significantes numa composição mais esquemática, visando decantar a história e traçar o caso a partir do discurso. Só assim será possível recolher dos infindáveis detalhes de uma história a direção de um caso. Enfim, uma história deve se fazer caso para que se possa trabalhar em psicanálise.

\section{Supervisão $\leftrightarrow$ Construção:}

As discussões realizadas em equipe sustentam o funcionamento de nosso método e remetem mais a um trabalho de construção do que de supervisão, ainda que no seu desenrolar tangenciem a experiência de supervisão. No entanto, diferem tanto do modelo do aprendiz/aluno quanto do praticante e, mesmo, de uma supervisão em grupo (intercontrole), já que não se trata de chegarmos à última palavra sobre qualquer conceito ou fenômeno. Convém lembrar que, decidir absolutamente sobre a verdade deste ou daquele caso estaria, por princípio, em contradição com uma supervisão verdadeiramente analítica. Porém, ao contrário da supervisão, a discussão não se encerra ao término da sessão, ela continua e remete-se ao pesquisador/analista que apresentou o caso. Num primeiro tempo, ocorre um retorno sobre ele em sua condição de sujeito (até aí não difere exatamente da supervisão). Num segundo tempo, trata-se da reapropriação do saber pelo analista na condição de pesquisador. Finalmente, este saber que é depositado é um produto. Este produto é o ponto de basta feito pelo pesquisador na condição de analista/praticante. O entrelaçamento das funções de sujeito, pesquisador, analista rompe qualquer fixidez de posição diante do saber. Portanto, sustentamos a construção - e não a super-visão - manejando os impasses que atravessam o cotidiano de nossa prática, apostando na formalização possível de seus princípios.

\section{Conceitos $\leftrightarrow$ Distinções:}

Os conceitos fundamentais da psicanálise são postos em questão a cada passo. Constatamos que não tem sido necessário definir exatamente o que eles significam nem a que evento correspondem em cada caso para que se obtenha o resultado esperado. Por outro lado, percebemos que é fundamental estabelecer algumas distinções sem as quais não há condução possível do caso. Por exemplo, em uma ocasião, delimitamos a importância de um enunciado como "eu não a quero mais, quero outra". Tal enunciado pode ser tomado como uma apresentação do sujeito do inconsciente, rompendo com os hábitos do eu, sempre cordato e 
submetido à sua esposa, repetindo-se em "eu a quero mais que as outras". Outro argumento seria que todo enunciado já está no campo do eu, pois o sujeito é sempre intervalar e evanescente. Mais do que definir se esse enunciado está no campo do eu ou do sujeito, trata-se de perceber que o fundamental é distinguir dois enunciados que correspondem a duas posições: "eu não a quero mais, quero outra", irrompe a partir de algo que insistia, até então silenciosamente. Ao passo que "eu a quero mais que as outras" é algo que permanece resistindo, agora explicitamente, estabelecendo os caminhos habituais do sujeito.

A psicanálise não é o efeito de um saber do Outro sobre uma história e, sim, o feliz encontro entre as ferramentas conceituais do analista - pulsão e objeto, por exemplo - e as contingências de uma história, produzindo um caso e, no melhor dos casos, um novo sujeito. Buscamos, assim, estar próximos da possibilidade de constituir enunciados positivos sobre este saber propriamente psicanalítico, singular e inventado a cada nova situação (Figueiredo et al., 2001).

\section{A construção do caso clínico em saúde mental}

No campo da saúde mental, vemos freqüentemente uma tendência a negar e mesmo a desqualificar a clínica, colocando-a no sentido contrário à reabilitação. Palavras de ordem como o direito à cidadania, à autonomia, à ampliação dos vínculos sociais parecem prescindir da clínica, como se essa fosse algo ultrapassado, ineficaz e até cronificante. Nada mais equivocado, pois a clínica no sentido radical, ao pé da letra, do discurso do sujeito é o único meio de escapar de duas grandes armadilhas insidiosas que são: a "pedagogia interpretativa", vício de uma certa tendência da psicanálise; e a "terapêutica da restauração", isto é, a terapêutica no sentido de fazer retornar ao estado anterior à doença.

A reabilitação só pode ser bem-sucedida na condição de seguir o estilo do sujeito (Viganò, 1999), o que remete à articulação que referimos acima entre sujeito e sintoma. O que se costuma chamar de "projeto terapêutico" deve ir na direção contrária à hierarquia dos saberes e funções que designam o que é necessário ou melhor para o paciente/usuário, e ir em busca das boas perguntas. Em vez de nos perguntarmos o que podemos fazer por ele, a pergunta deve ser feita de outro modo: o que ele pode fazer para sair de tal ou tal situação com nosso suporte. Isso significa de temos que suportar, no sentido mais radical da palavra, as ações do sujeito e chamá-lo à sua responsabilidade a cada vez, a cada ato.

Os exemplos são vários: é o paciente que foge toda hora, que transgride as normas e as leis o tempo todo, que não "adere" ao tratamento, ou não se "adequa" a determinada atividade ou ao "serviço", que vive entre o sistema jurídico civil ou 


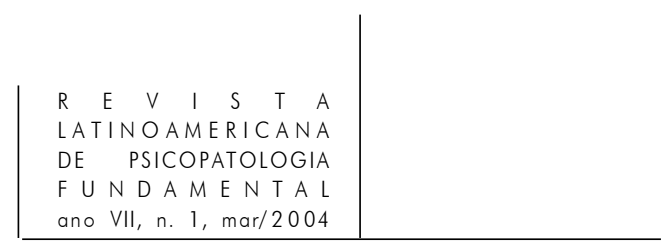

penal, sempre no limiar da inimputabilidade, por ser menor ou simplesmente louco. O melhor antídoto é a responsabilidade. Fazer o sujeito se perguntar o que faço aqui? O que torna minha vida tão insuportável, o que posso fazer para encontrar uma solução? São questões fundamentais que não surgem do nada, senão de um esforço conjunto do trabalho em equipe de não se deixar levar pelo furor sanandi, como já dizia Freud, e nem pelo furor de educar.

Se reabilitar denega a clínica, inevitavelmente caímos na armadilha da reeducação. Não que isso não aconteça, Freud mesmo já nos dizia que a psicanálise é uma espécie de reeducação, mas também nos avisou que as pulsões são ineducáveis, indomáveis. Eis o paradoxo.

$\mathrm{O}$ trabalho em equipe é extremamente complexo, e o modo como as equipes se estruturam também é decisivo para o destino da clínica. Destacamos duas lógicas ou modalidades de organização das equipes que podem melhor situar o problema. São elas: a formação hierárquica e a formação igualitária. Se as equipes são formadas mais na lógica hierárquica de funções e saberes, tendem a burocratizar a clínica, a verticalizar o poder e o saber, e a cristalizar as práticas. Se são mais igualitárias, tendem a horizontalizar o poder, a misturar as funções, escapando das especialidades (isso em si pode ser muito bom), mas caindo na falta de especificidade e confundindo as funções a ponto de perder a referência da clínica e imobilizar o trabalho conjunto (Figueiredo, 1997).

A equipe de saúde mental tem uma indicação preciosa no termo que Lacan usou para definir a relação de trabalho nos cartéis: "transferência de trabalho". Este termo permite que se dissolvam os efeitos narcísicos imaginários que inevitavelmente ocorrem, seja na confusão de papéis (modelo igualitário), seja na fixação de papéis (modelo hierárquico) (Figueiredo, 2000).

Quanto ao sujeito, o importante é seguir seu estilo para a partir daí lhe indagar o que é pertinente a seu sintoma, e fazê-lo tomar sua responsabilidade como tal, por seus atos, no mínimo que seja, mesmo que não tenha responsabilidade plena, no sentido jurídico. É preciso separar esse campo de responsabilidades porque, na maioria das vezes, os sujeitos se apresentam tutelados, desresponsabilizados, mas nem por isso sentindo-se menos culpados, ainda que se percebam como vítimas (em muitos casos o são de fato). Isso os leva à imobilidade, à falta de solução, à confirmação da doença. Se nesse momento lhes apresentamos o "remédio", sabemos que este não é a cura, nem a restituição pura e simples ao estado anterior à crise ou ao surto.

Promover um certo alívio do sofrimento e apaziguar a angústia é tarefa indispensável, mas como um meio e não como um fim, e essa diferença deve ser feita cotidianamente. Caso contrário, estamos indo mais na direção da cronificação, pois sabemos que há um incurável. Mas há também um movimento até esse limite que pode seguir vias aparentemente inusitadas se olharmos com olhos nor- 
malizadores. Não há restituição a um estado anterior no que se refere ao destino do sujeito, daí a função terapêutica ter um limite. Isso posto, uma boa posição para a equipe poderia ser, como diz Zenoni, a de "aprendizes da clínica" (Zenoni, 2000). Essa expressão sintetiza a posição da equipe em formular as boas questões, verificar os efeitos de suas intervenções, tomar novas decisões ou dar novo rumo a cada caso a partir das indicações do sujeito que, convém lembrar, não são tão óbvias ou intencionais, mas estão dadas de algum modo no seu sintoma, em suas diferentes manifestações.

Nesse ponto, retomamos o objeto central de nosso trabalho: a construção do caso clínico. Desta vez, nos voltamos para o trabalho em equipe nas instituições de saúde mental. A proposta é a mesma, recolher da experiência do sujeito, de seu discurso - que evidentemente tem um endereçamento, às vezes fragmentário, às vezes bem específico, a determinado profissional - os elementos com os quais se fará a construção do caso, entendendo que ela é sempre parcial, visa dar direções para determinada intervenção ou ação da equipe, sendo passível de revisão na medida dos acontecimentos.

A construção do caso pode conter elementos discursivos de familiares, de outros envolvidos, mas não pode perder o fio de meada que é a referência ao sujeito em questão. Voltamos aos binônios que nos servem como indicadores, como ferramentas da construção para serem aplicados no trabalho em equipe, diferente, portanto, de um trabalho de análise, mas contendo os elementos "possíveis" a partir das referências de cada sujeito, novamente: da história ao caso, da supervisão à construção, dos conceitos às distinções.

O que caracteriza a construção do caso na equipe de saúde mental, e diverge do trabalho mais específico do psicanalista, é exatamente o fato da equipe ser heterogênea em sua composição - diferentes profissionais e referências teóricotécnicas, diferentes níveis de formação. Mas é justamente por meio desse trabalho "coletivo" que a discussão do caso deve ir na direção do "aprendiz da clínica", ou seja, colher das produções do sujeito os indicadores para seu tratamento, e não, ao contrário, impor o modelo da reabilitação em sua dimensão pedagógica e moral, como acontece com frequiência.

Um exemplo prosaico pode nos ajudar a discernir nossa conduta: nos remetemos ao trabalho da equipe de um CAPS com o supervisor.

Trata-se de uma paciente adulta, por volta de seus trinta anos, com diagnóstico duvidoso de hebefrenia, e com suspeita de retardo mental (diagnóstico muito mais freqüente do que imaginamos), casada, tutelada pelo marido que a vigiava a cada passo, alegando sua condição. No CAPS, seu comportamento era bem "regredido", como diziam os profissionais da equipe. Quase não falava, tinha dificuldade de expressar-se, era pouco "cooperativa", e o que chamava mais a atenção da equipe era seu comportamento bizarro de andar pelos corredores de 


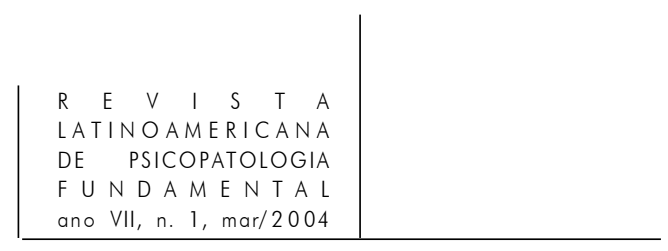

olhos fechados, como se não pudesse enxergar. Era capaz de ficar sentada de olhos fechados por muito tempo, recusando-se a falar; parecia ser mesmo um desses "casos graves". De vez em quando, participava de algumas atividades na oficina de culinária, ou de bordado, aí abria os olhos muito bem. Alegava-se que era a medicação que estava funcionando (e de fato estava!). Sabia-se, no entanto, que ela vivia fugindo do marido para ir ao encontro de um "amante", e parece que este não era o primeiro.

Quase como por acaso, a assistente social da equipe conhecia a família e sabia das histórias da vizinhança sobre ela (isso se passa numa cidade pequena, onde todos se conhecem). Quando ela estava aparentemente um pouco melhor, mais "cooperativa", saía de casa bem nos horários em que o marido trabalhava e não poderia vigiá-la, ia até o "amante" e voltava antes da hora dele chegar, enfim tinha um bom cálculo de seu comportamento para não levantar suspeitas, mas era "observada" pelos vizinhos que falavam entre si.

Em alguns momentos, ela confidencia com um dos técnicos de apoio (é o nome dado aos profissionais de nível médio) que não agüenta o marido, aquele jeito de tratar dela como se ela fosse uma boba, que gosta mesmo do outro fulano e quer fugir com ele daquele lugar. Tudo isso bem falado e dirigido a alguém que não é o doutor, apesar dela também ter falado disso com o médico, mas de um modo pueril, sem se fazer acreditar.

Somente na reunião da equipe é que foi possível discutir abertamente esses contrastes em seu comportamento, e colher esses elementos de sua fala que apontavam o sujeito, localizavam sua estratégia. Esse foi o passo preliminar para a construção do caso. O passo seguinte seria o de acolher sua fala mais sistematicamente, trazê-la à responsabilidade sobre suas ações sem culpabilizá-la ou dizer o que é melhor para ela. E então fazê-la construir sua história, que era contada pela vizinhança, mas não por ela, para a partir daí construir o caso ainda que parcialmente, e dar uma direção para a conduta da equipe que, até então, se limitava a "guardá-la" e ocupá-la para que o marido pudesse trabalhar.

$\mathrm{O}$ elemento diferencial nessa abordagem vem de uma atitude indicada pela psicanálise que pode ser tomada mesmo por não psicanalistas. Mas uma coisa é certa, é preciso que haja um despertar para a clínica nessa direção. A presença de um psicanalista poderia ajudar bastante, desde que este não se apresente como o portador da "boa nova" e sim como mais um "aprendiz" convocando os demais a fazerem o mesmo. Eis a diferença que importa, a contribuição que podemos dar. Esse caso não chegou a uma formulação próxima de uma construção. Por isso mesmo, não se sabia o que fazer diante do modo como esse sujeito se apresentava, e à equipe só restava atender à demanda do marido, acolhendo, cuidando, sem dúvida, medicando o sintoma, trazendo até mesmo um certo alívio por vezes, mas nunca trazendo à tona algo da verdade desse sujeito como produção sua, algo pelo 
que pudesse se responsabilizar em vez de se portar como uma espécie de pária social.

A construção do caso toca a verdade do sujeito e pode provocar situações de difícil manejo, mas não há como fugir disso, pois se o fizermos, estaremos abrindo mão de nosso mandato clínico e mantendo a cronificação que tanto condenamos pela conivência com a inércia da doença que leva à desresponsabilização, e com a inércia da instituição que leva ao imobilismo.

\section{Referências}

Figueiredo, A. C. Vastas confusões e atendimentos imperfeitos - a clínica psicanalítica no ambulatório público. 3. ed. Rio de Janeiro: Relume-Dumará, 2002.

Do atendimento coletivo ao individual: um atravessamento na transferência. Cadernos IPUB, Rio de Janeiro, v. VI, n. 17, p. 124-30, abr./2000.

Figueiredo A. C. \& Machado, O. R. Diagnóstico em psicanálise: do fenômeno à estrutura. Ágora - Estudos em Teoria Psicanalítica, Rio de Janeiro, v. III, n. 2, p. 6586, nov./2000.

O que faz um psicanalista na Saúde Mental. In: Cavalcanti, M. T. e VenÂncio, A. T. (org.). Saúde Mental: campo, saberes e discursos. Rio de Janeiro: CUCA-IPUB/ UFRJ, 2001, p. 73-81. (Coleções IPUB.)

Figueiredo, A. C. et al. Pesquisa clínica em psicanálise: a elaboração de um método, In: Figueiredo, A. C. (org.). Psicanálise, pesquisa e clínica. Rio de Janeiro: CUCAIPUB/UFRJ, 2001, p. 11-24. (Coleções IPUB.)

Figueiredo, A. C. \& Tenório, F. O diagnóstico em psiquiatria e psicanálise. Revista Latinoamericana de Psicopatologia Fundamental, São Paulo, v. V, n. 1, p. 29-43, mar./2002.

GARCIA, C. Saber e ciência: psicanálise, saúde pública e saúde mental. Cadernos IPUB, Rio de Janeiro, v. VIII, n. 21, p. 61-78, ago.-set./2002a.

Psicanálise, psicologia, psiquiatria e saúde mental: interfaces. Belo Horizonte: Ophicina de Arte e Prosa, 2002b.

Tenório, F. Psicanálise e reforma psiquiátrica: um trabalho necessário. In: Figueiredo, A. C. (org.). Psicanálise, pesquisa e clínica. Op. cit., p. 89-100.

VIGANò, C. A construção do caso clínico em saúde mental. Psicanálise e Saúde Mental Revista Curinga, Belo Horizonte, EBP/MG, n. 13, p. 50-9, set./1999.

Zenoni, A. Abrecampos - Psicanálise e instituição. Revista de Saúde Mental do Instituto Raul Soares, Belo Horizonte, IRS/FHEMIG, ano I, n. 0, 2000. 


\section{Resumos}

Este texto presenta una propuesta de construcción del caso clínico a partir del desarrollo de la investigación clínica en psicoanálisis. Se destacan tres ejes de ese procedimiento como indicadores metodológicos para el manejo de elementos extraídos de los relatos de los sujetos, presentándose segundo los siguientes binomios: historial caso; supervisión/construcción; conceptos/distinciones. La construcción del caso es el punto central de la contribución del psicoanálisis tanto para la psicopatología, a través de la construcción diagnostica y de los indicadores para el tratamiento, cuánto para la salud mental, a través de su aplicación en los distintos dispositivos de atención psico-social y en el trabajo en equipo interdisciplinario.

Palabras clave: Caso clínico, psicoanálisis, psicopatología, salud mental

Ce texte présente une proposition de construction du cas clinique à partir du développement de la recherche clinique en psychanalyse. Trois axes de ce procédé sont ici choisis comme indicateurs méthodologiques pour le maniement d'éléments extraits des récits des sujets, et peuvent être exprimés selon les binômes suivant : histoire/cas; supervision/construction; concepts/distinctions. La construction du cas est le point central de l'apport de la psychanalyse aussi bien à la psychopathologie, grâce à la construction diagnostique et aux indicateurs pour le traitement, qu'à la santé mentale, par son application dans les différents dispositifs d'attention psychosociale et dans le travail en équipe interdisciplinaire.

Mots clés: Cas clinique, psychanalyse, psychopathologie, santé mentale

This text presents the case-building method based on clinical research developed in psychoanalysis. Three axes of this procedure are pointed out as methodological tools to deal with elements obtained from the subjects' accounts, which consist of the following binomials: history/case; supervision/construction; concepts/distinctions. Case building is the core of psychoanalysis's contribution to psychopathology as a diagnostic tool and an orientation in treatment, as well as its contribution to mental health through its application in different modes of psychosocial attention and in interdisciplinary work.

Key words: Clinical case, psychoanalysis, psychopathology, mental health

Versão inicial recebida em setembro de 2003

Versão revisada recebida em outubro de 2003 